\title{
Validating Techniques for Measurement of Cutaneous Neurofibromas
}

\author{
Recommendations for Clinical Trials
}

Raquel D. Thalheimer, BA, Vanessa L. Merker, PhD, K. Ina Ly, MD, Amanda Champlain, MD, Jennifer Sawaya, MD, Naomi L. Askenazi, Hamilton P. Herr, BA, Jennifer L.W. Da, BA, Justin T. Jordan, MD, MPH, Alona Muzikansky, MA, Elizabeth Morehouse Pearce, BA, Fernanda H. Sakamoto, MD, PhD, Jaishri O. Blakeley, MD, R. Rox Anderson, MD, and Scott R. Plotkin, MD, PhD, on behalf of the REiNS International Collaboration

Neurology ${ }^{\circledR}$ 2021;97:S32-S41. doi:10.1212/WNL.0000000000012428

\begin{abstract}
Objective

To assess the reliability and variability of digital calipers, 3D photography, and high-frequency ultrasound (HFUS) for measurement of cutaneous neurofibromas (cNF) in patients with neurofibromatosis type 1 (NF1).
\end{abstract}

\section{Background}

cNF affect virtually all patients with NF1 and are a major source of morbidity. Reliable techniques for measuring $\mathrm{cNF}$ are needed to develop therapies for these tumors.

\section{Methods}

Adults with NF1 were recruited. For each participant, $6 \mathrm{cNF}$ were assessed independently by 3 different examiners at 5 different time points using digital calipers, 3D photography, and HFUS. The intraclass correlation coefficient (ICC) was used to assess intrarater and interrater reliability of linear and volumetric measurements for each technique, with ICC values $>0.90$ defined as excellent reliability. The coefficient of variation $(\mathrm{CV})$ was used to estimate the minimal detectable difference (MDD) for each technique.

\section{Results}

Fifty-seven cNF across 10 participants were evaluated. The ICC for image acquisition and measurement was $>0.97$ within and across examiners for HFUS and 3D photography. ICC for digital calipers was $0.62-0.88$. CV varied by measurement tool, linear vs volumetric measurement, and tumor size.

\section{Conclusions}

HFUS and 3D photography demonstrate excellent reliability whereas digital calipers have good to excellent reliability in measuring cNF. The MDD for each technique was used to create tables of proposed thresholds for investigators to use as guides for clinical trials focused on cNF size. These criteria should be updated as the performance of these end points is evaluated.

\footnotetext{
From the Department of Neurology and Cancer Center (R.T., V.L.M., I.L., N.L.A., H.P.H., J.L.W.D., J.T.J., S.R.P.), Wellman Center for Photomedicine (A.C., J.S., E.M.P., F.H.S., R.R.A.), and Biostatistics Center (A.M.), Massachusetts General Hospital, and Department of Dermatology (A.C., J.S., E.M.P., F.H.S., R.R.A.), Harvard Medical School, Boston; and Department of Neurology, Neurosurgery, and Oncology (J.B.), Johns Hopkins University School of Medicine, Baltimore, MD.

Go to Neurology.org/N for full disclosures. Funding information and disclosures deemed relevant by the authors, if any, are provided at the end of the article.
} 


\section{Glossary}

$\mathrm{cNF}=$ cutaneous neurofibroma; $\mathbf{C V}=$ coefficient of variation; HFUS $=$ high-frequency ultrasound; $\mathbf{I C C}=$ intraclass correlation coefficient; MDD = minimal detectable difference; NF1 = neurofibromatosis type 1; REiNS = Response Evaluation in Neurofibromatosis and Schwannomatosis.

Neurofibromatosis type 1 (NF1) is an autosomal dominant genetic disorder characterized by multiple nervous system tumors, including cutaneous neurofibromas (cNF), which affect $>90 \%$ of adults with NF1. ${ }^{1}$ Although these tumors do not have malignant potential, they often cause pain, itching, and disfigurement, and are associated with impaired quality of life. ${ }^{2,3}$ Most cNF are small (typically $1-30 \mathrm{~mm}$ ) but they can number in the thousands, involving all areas of skin and resulting in life-altering disfigurement. ${ }^{4}$ They develop throughout life, and there are no known effective, nonsurgical therapies to treat or prevent these lesions. The mainstay of treatment is either surveillance or surgical excision of individual tumors. Beyond surgery, modalities that have been used for treatment include electrodessication, lasers, radiofrequency ablation, and investigational topical and systemic drug therapies. ${ }^{5-12}$ However, none of these modalities have been assessed in multicenter studies, and there is no standard approach to response evaluation for $\mathrm{cNF}^{13,14}$

A major limitation in developing new treatments for $\mathrm{cNF}$ is the inability to reliably measure these tumors. Previous studies have explored the reliability of calipers to assess the size of plaster models of $\mathrm{cNF}$ and of high-frequency ultrasound (HFUS) to identify ultrasonographic features of cNF. ${ }^{15,16}$ Digital photography has been used to assess cNF improvement in clinical trials (NCT01031901). No data on the reliability of these techniques in persons with NF1 have been published. This study assessed the feasibility, reliability, and variability of digital calipers, 3D photography, and HFUS to measure $\mathrm{cNF}$ in clinical trials.

\section{Methods}

\section{Study Design}

Participants were identified and recruited through the Neurofibromatosis Clinic at Massachusetts General Hospital in Boston. This study was approved by the Massachusetts General Hospital institutional review board. Inclusion criteria included a diagnosis of NF1, age $\geq 18$ years, presence of at least 6 visible cutaneous neurofibromas, and ability to give informed consent in English. Exclusion criteria included inability to tolerate imaging procedures. The primary end point was intrarater and interrater reliability of HFUS for cNF. Secondary end points included ability of HFUS to detect change in cNF size over time, feasibility of HFUS, intrarater and interrater reliability of digital calipers and 3D photography, and patient-reported outcomes.

To assess intrarater and interrater reliability, 3 examiners assessed $6 \mathrm{cNF}$ in 10 participants at 3 time points at least 15 minutes apart on the same day using digital calipers, 3D photography, and HFUS. The same $6 \mathrm{cNF}$ were measured to assess longitudinal changes in cNF size across 4 study visits over the course of 12 months: months 0 (baseline), 4,8 , and 12. Participants completed quality of life surveys including Skindex-29, ${ }^{17}$ Impact of NF1 on Quality of Life, ${ }^{18}$ and 5-D Pruritus Scale at baseline and month 12 . The analysis of reliability and variability in the baseline assessment of $\mathrm{cNF}$ is presented in this article. The feasibility of techniques was assessed by recording the time spent performing HFUS, 3D camera image analysis, and digital caliper assessment. These times were averaged for each patient ( 6 tumors per patient) and for each tumor, including setup. Cost of acquiring hardware and software was used as a metric of accessibility of techniques.

\section{Image Acquisition}

Prior to imaging, 6 nonpedunculated cNF were selected on the participant's arms to minimize artifact from movement and for patient convenience. Two methods were used to track individual cNF across study visits: (1) a permanent map was created by marking the location of cNF on a plastic sheet placed over the participant's arm and (2) a 2D photograph of the anatomic region with the marked cNF targets in relation to other anatomical landmarks - for example, a nevus, birthmark, or scar.

\section{High-Frequency Ultrasound}

HFUS imaging was performed using the Vevo3100 System (Fujifilm VisualSonics). To image cNF, $12-25 \mathrm{~mL}$ of Aquasonic ultrasound gel (Cardinal Health) were placed over the tumor, and the transducer (range, $22-55 \mathrm{MHz}$; center frequency $30 \mathrm{MHz}$ ) was positioned directly above the tumor using a tripod for stabilization. All images were reviewed manually for quality prior to inclusion in the analysis.

\section{D Photography}

3D photographs were obtained using Vectra H1 3D camera (Canfield Scientific) according to the manufacturer's recommendation.

\section{Digital Calipers}

cNF were measured with digital calipers (World Precision Instruments). The width, length, and height of each tumor were measured and recorded on a paper form. To assess tumor width, the caliper was adjusted to measure the maximum distance parallel to the participant's wrist. The caliper was zeroed, and the forks were adjusted so that they included the visible tumor, but not the surrounding skin. For elevated tumors, the caliper was placed flush to the skin and adjusted 
until the forks touched the outer edges but did not distort tumor shape. The same process was repeated for the length measurement, which was the maximum distance perpendicular to the width. To assess height, a tongue depressor was positioned so that the base touched the surrounding unaffected skin and the side was even against the tumor. The maximum height of the tumor was marked against the tongue depressor and measured using digital calipers.

\section{Image Analysis}

Ultrasound images and 3D photographs were analyzed offline using standard software according to the manufacturer's recommendations (FujiFilm Visual Sonics for ultrasound and Vectra H1 software for 3D photographs). For HFUS, volume, width, and depth of cNF were measured; for 3D photographs, volume, surface area, width, and length were measured. Linear measures (length, width) for 3D photography were calculated using both automated and manual measurements to assess maximum cross width and a corresponding perpendicular length (table 1). For digital calipers, tumor width, length, and height were measured, and an approximate ellipsoid volume was calculated for each cNF. An example of measurement techniques is shown in figure 1.

\section{Statistical Assessment}

The Response Evaluation in Neurofibromatosis and Schwannomatosis (REiNS) International Collaboration has previously recommended percent change from baseline (rather than absolute change from baseline) to assess imaging response in NF. ${ }^{19}$ One consequence of this approach is that a given change in size represents a larger percent change for small cNF than for large cNF. In order to study this issue, we used a statistical definition to define small and large tumors. The cutoff value was defined as the median tumor diameter rounded up to the nearest integer (in millimeters). Large tumors were defined as $\geq 5 \mathrm{~mm}$ in maximum diameter and small tumors were defined as $<5 \mathrm{~mm}$ in maximum diameter, as measured by calipers.

The intrarater and interrater reliability of HFUS, 3D photography, and digital calipers for the first 10 participants was assessed using intraclass correlation coefficients (ICCs). ICCs range from 0 to 1 with $0.9-1.0$ considered excellent, $0.75-0.89$ good, $0.5-0.74$ moderate, and $<0.5$ poor reliability. The ICC was calculated for 2 possible sources of variability in the measurements: image acquisition and tumor measurement. This approach yielded 4 ICC measures per technique (i.e., intrarater and interrater reliability for image acquisition and tumor measurement). Digital calipers did not have ICC values for image acquisition because acquisition and analysis occur simultaneously.

The coefficient of variation (CV) was used to compare the variability of $1 \mathrm{D}$ (linear), 2D (area), and 3D (volume) measurement of HFUS, 3D photography, and digital calipers. We defined the minimal detectable difference (MDD) for each technique as at least twice the $\mathrm{CV}$ to detect the smallest change that is not the result of measurement variability. The MDD was used to create tables of proposed thresholds for investigators to use in clinical trials directed at evaluating $\mathrm{cNF}$ response for therapeutic interventions.

\section{Data Availability}

Nonidentifying clinical data will be uploaded to the Synapse online data-sharing platform (synpase.org) maintained by Sage Bionetworks.

\section{Results}

\section{Study Cohort}

The median age of the 10 participants was 53 years (range, 36-67 years). Half of participants were female, and the majority were non-Hispanic and White (table 2). In total, 57 tumors were included in this analysis (the first patient had 2 tumors that were believed to represent scar on image analysis). The median tumor diameter was $4.2 \mathrm{~mm}$ (range $2.4-11.4 \mathrm{~mm})$. There were $24(42 \%)$ large tumors $(\geq 5 \mathrm{~mm}$ in maximum diameter) and $33(58 \%)$ small tumors $(<5 \mathrm{~mm}$ in maximum diameter) included in the analysis.

\section{Reliability of Measurement Techniques}

Figure 2 summarizes the intrarater and interrater ICCs of the 3 measurement techniques. All ICC values for HFUS were consistently excellent (ICC $\geq 0.9$ ). Similarly, nearly all ICC

Table 1 Comparison of Measures Determined by Digital Calipers, 3D Photography, and High-Frequency Ultrasound (HFUS)

\begin{tabular}{|c|c|c|c|c|}
\hline Dimension & Caliper & $\begin{array}{l}\text { Photography (manual } \\
\text { measurement) }\end{array}$ & $\begin{array}{l}\text { Photography (automated } \\
\text { measurement) }\end{array}$ & HFUS \\
\hline \multirow[t]{3}{*}{ Linear (1D) } & Width & Width & Width & Width \\
\hline & Length & Length & Length & - \\
\hline & $\begin{array}{l}\text { Height (above } \\
\text { skin) }\end{array}$ & - & - & $\begin{array}{l}\text { Depth (above and below } \\
\text { skin) }\end{array}$ \\
\hline $\begin{array}{l}\text { Surface area } \\
\text { (2D) }\end{array}$ & - & - & Surface area & - \\
\hline Volume (3D) & Ellipsoid volume & Volume & - & Volume \\
\hline
\end{tabular}


Figure 1 Representative Images for Measurement of Cutaneous Neurofibroma (cNF)
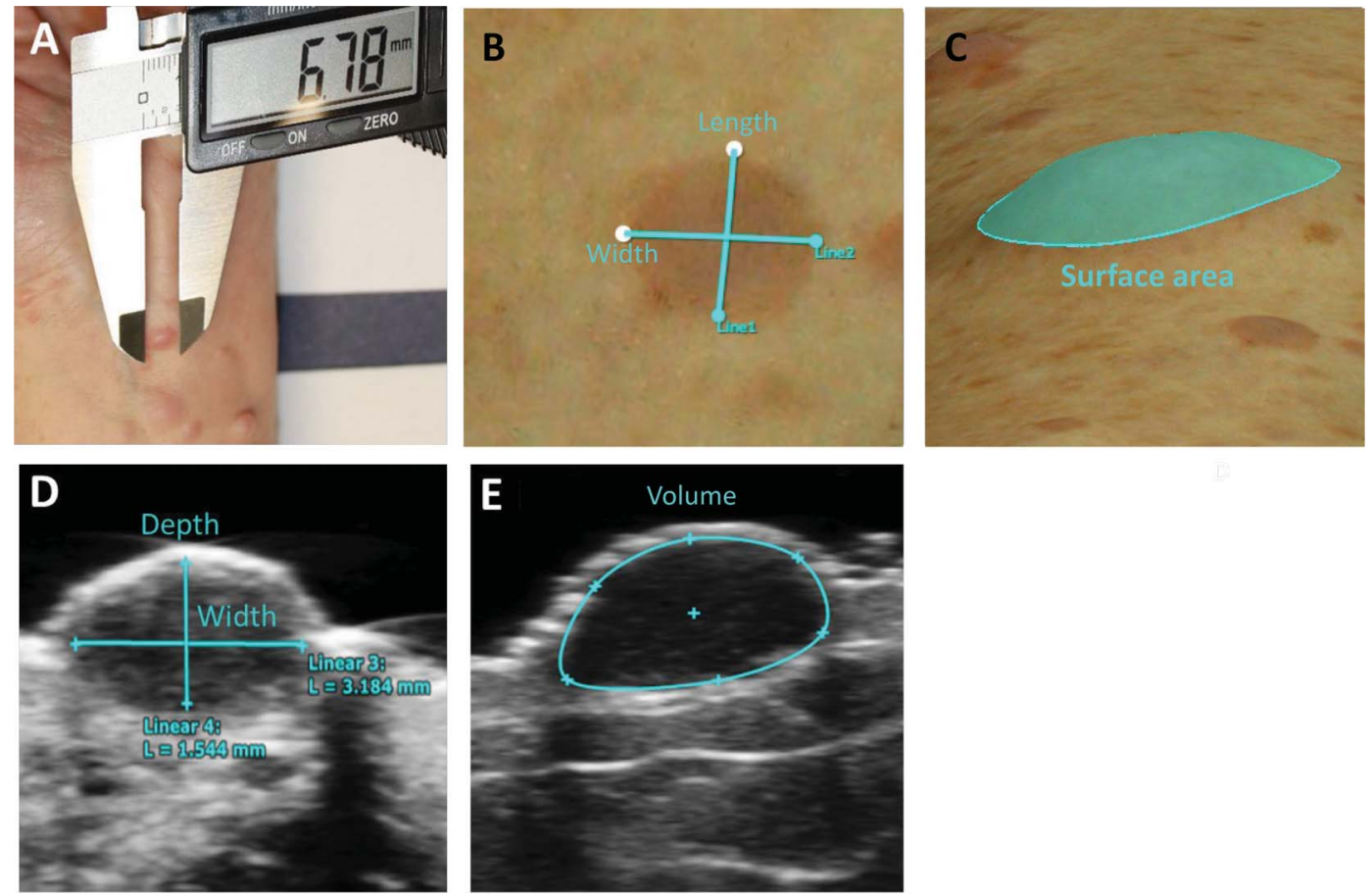

(A) Measurement of CNF using digital calipers. (B) Manual length and width using 3D photography. (C) Automated length, width, and surface area using 3D photography. (D) Depth and width using high-frequency ultrasound (HFUS). (E) Volume using HFUS. Hypoechoic (dark) areas on HFUS correspond to $\mathrm{CNF}$.

Table 2 Demographics and Tumor Characteristics of Participants

\begin{tabular}{ll}
\hline Feature & Value \\
\hline Participants, $\mathbf{n}$ & 10 \\
\hline Age, $\mathbf{y}$ & $53(36-67)$ \\
\hline Sex (female) & $5(50)$ \\
\hline Ethnicity & \\
\hline Non-Hispanic & $8(80)$ \\
\hline Hispanic & $1(10)$ \\
\hline Declined & $1(10)$ \\
\hline Race & $9(90)$ \\
\hline White & $1(10)$ \\
\hline Asian & 57 \\
\hline Cutaneous neurofibromas & \\
\hline measured, $\mathbf{n}$ & $4.2(2.4-11.4)$ \\
\hline Diameter, mm & $33(58)$ \\
\hline$<5$ & $24(42)$ \\
\hline$\geq 5$ & \\
\hline &
\end{tabular}

Values are median (range) or $\mathrm{n}(\%)$. values for 3D photography were excellent except for interrater ICC of image acquisition using automated length measurements (ICC 0.87; good). The lowest ICCs were observed for digital calipers. Because acquisition and analysis for digital calipers occur simultaneously, only analysis reliability is reported for this method. The intrarater ICC values for digital caliper were excellent (ICC $\geq 0.9$ ) except for height (ICC 0.81 ; good). By contrast, the interrater ICC values were lower; good (ICC 0.85-0.88) except for height (ICC 0.62; moderate).

\section{Minimal Detectable Difference for Each Technique}

The $\mathrm{CV}$ and $\mathrm{MDD}$ for the 3 measurement techniques are listed in figure 3. In general, linear measures had smaller CV than volumetric measures for all 3 techniques, ranging from $5.2 \%$ to $13.4 \%$ depending on technique, tumor size, and type of linear measurement. These smaller $\mathrm{CV}$ values produce smaller MDD values as well. The $\mathrm{CV}$ for linear measures was smaller for $3 \mathrm{D}$ photography and HFUS than for digital calipers and was smaller for measuring $\mathrm{cNF} \geq 5 \mathrm{~mm}$ than for $\mathrm{cNF}<5 \mathrm{~mm}$.

\section{Time for Image Acquisition and Image Analysis}

For image acquisition, the median time required per patient was 5 minutes for HFUS, less than 30 seconds for 3D photography, and 6 minutes for digital calipers. For image analysis, the median time per patient was as follows: 7 minutes for HFUS 
Figure 2 Intraclass Correlation Coefficient (ICC) Results for Caliper Measurements, 3D Photography, and High-Frequency Ultrasound (HFUS)

\begin{tabular}{|c|c|c|c|c|}
\hline & \multicolumn{2}{|c|}{ Image Acquisition Reliability } & \multicolumn{2}{|c|}{ Image Analysis Reliability } \\
\hline & Intra-rater ICC & Inter-rater ICC & Intra-rater ICC & Inter-rater ICC \\
\hline \multicolumn{5}{|l|}{ HFUS } \\
\hline Volume & 0.98 & 0.97 & 0.99 & 0.98 \\
\hline Width & 0.98 & 0.98 & 0.98 & 0.99 \\
\hline Depth & 0.98 & 0.97 & 0.99 & 0.97 \\
\hline \multicolumn{5}{|l|}{ 3D Camera } \\
\hline Volume & 0.97 & 0.95 & 0.98 & 0.98 \\
\hline Width (manual) & 0.97 & 0.96 & 0.97 & 0.98 \\
\hline $\begin{array}{l}\text { Width } \\
\text { (automated) }\end{array}$ & 0.96 & 0.96 & 0.98 & 0.97 \\
\hline $\begin{array}{l}\begin{array}{l}\text { Length } \\
\text { (manual) }\end{array} \\
\text { (mal }\end{array}$ & 0.97 & 0.96 & 0.98 & 0.98 \\
\hline $\begin{array}{l}\text { Length } \\
\text { (automated) }\end{array}$ & 0.97 & 0.87 & 0.91 & 0.93 \\
\hline Surface Area & 0.98 & 0.97 & 0.99 & 0.98 \\
\hline \multicolumn{5}{|l|}{ Calipers } \\
\hline Volume & & & 0.9 & 0.77 \\
\hline Width & & & 0.96 & 0.88 \\
\hline Length & & & 0.93 & 0.85 \\
\hline Height & & & 0.81 & 0.62 \\
\hline
\end{tabular}

\begin{tabular}{|l|l|}
\hline ICC & Reliability \\
\hline$<.5$ & Poor \\
\hline $0.5-.75$ & Moderate \\
\hline $0.75-0.9$ & Good \\
\hline $0.9-1.0$ & Excellent \\
\hline
\end{tabular}

Image acquisition refers to the real-time process of acquiring images. Image analysis was performed offline after image acquisition. Reliability was assessed for both steps. linear analysis (range 5.0-10.5 minutes), 21.5 minutes for HFUS volume analysis (range 16.5-45.5 minutes), 8.0 minutes for 3D photography-based manual linear analysis (range 5.0-11.0 minutes), 10.0 minutes for 3D photography-based automated linear analysis (range 6.0-12.0 minutes), and 9.5 minutes for 3D photography-based volume analysis (range 7.0-15.0 minutes). No time was required for analysis of digital caliper-based measurements. Notably, image analysis for both HFUS and 3D photography yields durable data files with raw and processed images. There are no durable data files for digital calipers.

\section{Cost of Hardware and Software}

The cost of the hardware and software used in this study was approximately $\$ 225,000$ for HFUS, $\$ 13,400$ for 3D photography, and $\$ 100$ for digital calipers.

\section{Discussion}

We assessed 3 techniques for measurement of the cNF size in adults with NF1 with the goal of establishing metrics to support their use in clinical trials. Each technique has strengths and weaknesses for consideration by investigators. HFUS and 3D photography had excellent reliability for image acquisition and analysis within raters and across different raters. In contrast, caliper measurements showed less reliability with weakest performance when measuring the height of cNF both within and across raters.

We then evaluated the variability of measurements to propose thresholds for each technique that would allow accurate assessment of tumor growth/shrinkage. First, the variability of measurement for small $\mathrm{cNF}(<5 \mathrm{~mm})$ was greater than for

Figure 3 Variability of Measurement as Estimated by Coefficient of Variation (CV) for Caliper Measurements, 3D Photography, and High-Frequency Ultrasound (HFUS)

\begin{tabular}{|c|c|c|c|c|}
\hline & $\begin{array}{l}\text { Small eNF } \\
\text { CV }\end{array}$ & $\begin{array}{c}\text { Large cNF } \\
\text { CV }\end{array}$ & $\begin{array}{l}\text { Proposed threshold } \\
\text { for small cNF }\end{array}$ & $\begin{array}{l}\text { Proposed threshold } \\
\text { for large cNF }\end{array}$ \\
\hline \multicolumn{5}{|l|}{ Calipers } \\
\hline Width & $19.0 \%$ & $10.6 \%$ & \multirow{2}{*}{$40 \%$} & \multirow{2}{*}{$25 \%$} \\
\hline Length & $17.8 \%$ & $13.0 \%$ & & \\
\hline Height & $38.7 \%$ & $25.0 \%$ & $75 \%$ & $50 \%$ \\
\hline Volume & $63.2 \%$ & $33.4 \%$ & $\mathrm{n} / \mathrm{a}$ & $70 \%$ \\
\hline \multicolumn{5}{|l|}{ 3D Camera } \\
\hline Width (manual) & $11.80 \%$ & $7.00 \%$ & \multirow{4}{*}{$25 \%$} & \multirow{4}{*}{$25 \%$} \\
\hline Width (automated) & $10.2 \%$ & $7.6 \%$ & & \\
\hline Length (manual) & $10.7 \%$ & $6.6 \%$ & & \\
\hline Length (automated) & $10.9 \%$ & $9.9 \%$ & & \\
\hline Surface Area & $18.7 \%$ & $12.2 \%$ & $40 \%$ & $25 \%$ \\
\hline Volume & $57.2 \%$ & $18.6 \%$ & $\mathrm{n} / \mathrm{a}$ & $40 \%$ \\
\hline \multicolumn{5}{|l|}{ HFUS } \\
\hline Width & $13.4 \%$ & $5.9 \%$ & \multirow{2}{*}{$30 \%$} & \multirow{2}{*}{$15 \%$} \\
\hline Depth & $11.6 \%$ & $5.2 \%$ & & \\
\hline
\end{tabular}

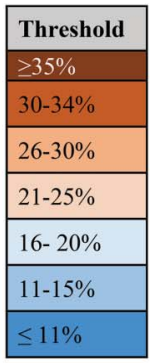

Small cutaneous neurofibroma (cNF) are $<5 \mathrm{~mm}$ in diameter; large cNF are $\geq 5 \mathrm{~mm}$ in diameter. The minimal detectable difference (MDD) for each technique was defined as at least twice the CV. The MDD was used to propose thresholds for investigators to use in clinical trials directed at evaluating imaging response for interventions. 
large $\mathrm{cNF}(\geq 5 \mathrm{~mm})$, raising concerns about accurate measurement of small tumors in clinical trials designed to shrink tumors. Second, HFUS and 3D photography have less variability in measurement than digital calipers and are amenable to central review, which can remove the potential for reader bias and promote standardization of response assessment. Third, volume measurements demonstrated greater variation than linear measures across all measurement tools: the overall CV for cNF volume using HFUS, 3D photography, and digital caliper was $29.5 \%, 43.2 \%$, and $51.8 \%$, as compared with $\mathrm{CV}$ for linear measures of $15 \%, 10 \%$, and $10 \%$. Measuring longest diameter parallel to the skin has the least variability and can be used for linear or bidimensional measurements of $\mathrm{cNF}$.

Equipment cost, required training, and execution time should be considered when selecting the most appropriate measurement tool and measurement type for a cNF clinical trial. $3 \mathrm{D}$ photography was the most feasible technique for participants, as assessed by time required for image acquisition; digital calipers were most feasible for investigators as assessed by time required for image analysis. The cost of the HFUS machine (approximately $\$ 225,000$ ) is prohibitive for many research groups. The $3 \mathrm{D}$ camera was more moderately priced at $\$ 13,400$ (including laptop and software), and digital calipers were affordable (approximately \$100). In addition, use of HFUS equipment requires substantial training. To assure quality results, researchers must be trained in appropriate ultrasound technique and image optimization, in addition to learning the corresponding Vevo measurement software. However, our results indicate that raters can achieve excellent reliability (ICC $\geq 0.97$ ) following appropriate training. Image acquisition using the $3 \mathrm{D}$ camera requires training as well, but significantly less than for HFUS. The 3D photography software requires training, but researchers can also achieve excellent reliability (ICC $\geq 0.91$ ) with appropriate training. Digital calipers require minimal training and do not require postvisit analysis. However, while intrarater reliability is in the good to excellent range (ICC $\geq 0.81$ ), the interrater reliability of image analysis falls within the moderate to good range $($ ICC $\geq 0.62)$.

The goal of developing cNF response criteria is to detect the smallest clearly measurable difference in size of $\mathrm{cNF}$ as a sign of activity of an investigational agent or device. Based on these findings and in consultation with the REiNS cNF working group (see Cannon et al. in this supplement), we developed the following recommendations for assessing $\mathrm{cNF}$ in clinical trials.

\section{General Recommendations for Measuring cNF}

\section{Measurable cNF}

Measurable cNF must be surrounded by normal-appearing skin to demarcate the lesion. For example, cNF abutting other cNF or those obscured by rashes or hair are not considered measurable. Pedunculated cNF with a narrow stalk and broad body are not suitable for study given their irregular shape that is difficult to assess by current measurement techniques. ${ }^{20}$

\section{Tracking Individual cNF in Clinical Trials for Accurate Repeat Measures}

Given the large number of cNF in most patients with NF1, a tracking system is essential to ensure that the same cNF are measured throughout the study. In our study, the use of $2 \mathrm{D}$ photography to document target $\mathrm{cNF}$ in relation to cutaneous landmarks in combination with a permanent map created by marking the location of $\mathrm{cNF}$ on a plastic sheet template placed over the participant's arm was effective in tracking individual cNF. These techniques, or others as appropriate, should be defined by the study prior to enrollment of participants.

\section{Minimizing Variability}

The group does not recommend the use of double baseline measurements for cNF trials but does recommend using the same technician to acquire images or caliper measurements throughout the trial and use of central review for image analysis of 3D photographs and HFUS images.

\section{Confirmatory Measurement}

Confirmation of $\mathrm{cNF}$ response at least 4 weeks after response is desirable to minimize the rate of false-positive or falsenegative responses.

\section{Recommended Outcomes for HFUS}

For clinical trial outcomes, the group considered the following measures as end points: width and depth (linear measures) and volume (table 1). The group recommended HFUS for measurement of small and large cNF given the low variability for all cNF sizes. The group recommended use of HFUS linear measures (depth or width) as outcome measures because (1) depth is a clinically meaningful measure of cNF size that may be particularly important to patients; (2) HFUS is the only technique that can measure the amount of cNF beneath the skin; (3) variability of cNF volume was high, limiting the use of this variable in clinical trials; and (4) HFUS images can be reviewed centrally.

\section{Feasibility}

The cost of HFUS devices limits the availability of this technique in NF clinics. Furthermore, the technique cannot be easily integrated into a clinic setting given the size of the device. Training of personnel is essential to minimize variability, and measurements should ideally be performed by the same individual throughout the study.

\section{Baseline Evaluations}

The working group recommended that a minimum of $5 \mathrm{cNF}$ should be identified as target lesions and recorded and measured at baseline. The maximum depth and width for each lesion should be recorded. Each study protocol should identify whether maximum depth or width will be used as a reference by which to characterize individual cNF responses; the same dimension should be measured over time to determine response. The orthogonal dimension (e.g., maximum width if maximum depth is used as reference) should also be used as a reference for an exploratory outcome in the trial. In addition, the sum of depths or widths for all target lesions will be 
calculated and reported as the baseline sum depth for exploratory analyses. The baseline sum longest diameter will be used as the reference by which to characterize the collective tumor response.

\section{Response Criteria}

HFUS response criteria are defined in reference to the baseline maximum depth or width of individual $\mathrm{cNF}$ at study initiation. Our study suggests that $\mathrm{cNF}<5 \mathrm{~mm}$ at baseline (small cNF) demonstrate more variability in measurement than cNF larger than $5 \mathrm{~mm}$ (large $\mathrm{cNF}$ ). Thus, the group recommended a greater percentage change in maximum depth or width for small cNF (30\%) than for large cNF (15\%) in order to minimize the rate of false-positive or false-negative responses. In addition, the group recommends using change in the sum of maximum depth or width as an exploratory end point.

cNF shrinkage is defined as a relative decrease in the width or depth of $30 \%$ for small cNF and of $15 \%$ for large cNF. cNF growth is defined as a relative increase in the longest diameter of $30 \%$ for small cNF and of $15 \%$ for large cNF. Stable size is defined as all other changes. For studies using the sum of longest diameters, $\mathrm{cNF}$ shrinkage or growth is defined as a relative decrease or increase, respectively, of $15 \%$ in the sum of longest diameters.

\section{Special Notes on High-Frequency Ultrasound}

This technique is uniquely able to image tumor beneath the skin and is well suited for nascent cNF that are minimally raised and not easily measured by calipers or 3D photography. Due to its low variability, HFUS is the only technique recommended for use in cNF smaller than $5 \mathrm{~mm}$ in longest diameter. Hence, this may be a technique that is particularly valuable in prevention studies. It is unknown whether changes in width or depth are more closely associated with patient benefit. Thus, the proposed response criteria allow individual studies to choose either width or depth to measure as primary outcome for individual cNF.

\section{Recommended Outcomes for 3D Photography} For clinical trial outcomes, the group considered the following measures as end points: manual and automated measurement of length/width (linear measures), surface area, and volume (table 1 ). The group recommended use of $3 \mathrm{D}$ photography to measure surface area as an outcome measure for large cNF ( $\geq 5 \mathrm{~mm}$ ) because (1) surface area is a reliable and clinically meaningful measure of cNF size; (2) 3D photographs are easy to acquire; (3) 3D photographs can be reviewed centrally; and (4) 3D photography can be used to monitor a large number of $\mathrm{cNF}$ with minimal effort for participant or examiner. In addition, the group recommended collecting automated length or width (linear measure) and volume of $\mathrm{cNF}$ as exploratory end points. Measurement of surface area was preferred over linear measures as the former incorporates elevation above the skin, an important component of tumor visibility, and over volumetric measures given the reduced variability of measuring surface area. For small $\mathrm{cNF}(<5 \mathrm{~mm})$, the group recommended use of linear measures as an outcome; this was preferred over surface area or volumetric measures given the reduced variability of measuring linear dimensions.

\section{Feasibility}

3D cameras are widely available, of moderate cost for clinical research, and can be easily integrated into a clinic setting. In order to minimize variability, measurements should be performed on $\mathrm{cNF} \geq 5 \mathrm{~mm}$ by trained personnel and analyzed by a central facility.

\section{Baseline Evaluation}

The working group recommended that a minimum of 5 lesions should be identified as target lesions and recorded and measured at baseline. The surface area for each lesion will be measured using the manufacturer's software and recorded. The individual surface areas will be used as a reference by which to classify individual cNF response. In addition, the longest diameter and volume for each lesion and the sum of surface areas for all target lesions will be calculated. The individual longest diameters, volume, and baseline sum surface area will be used as the reference by which to characterize the collective tumor response for exploratory studies.

\section{Response Criteria}

$3 \mathrm{D}$ photography response criteria are defined in reference to the baseline surface area of individual cNF at study initiation. The group recommends change in surface area as the primary imaging end point (table 2 ). The group recommends using change in longest diameter for each lesion, in volume, and in the sum of surface area for all $\mathrm{cNF}$ as exploratory end points. In addition, the group recommended studying changes in appearance (e.g., coloration) as an outcome measure.

cNF shrinkage is defined relative to baseline as a decrease in surface area of $25 \%$. cNF growth is defined relative to baseline as an increase in the surface area of $25 \%$. Stable size is defined as all other changes. For studies using longest diameter, cNF shrinkage or growth is defined as a relative decrease or increase, respectively, of $25 \%$ compared with baseline. For studies using volume, cNF shrinkage or growth is defined as a relative decrease or increase, respectively, of $70 \%$ compared with baseline. For studies using the sum of longest diameters, cNF shrinkage or growth is defined as a relative decrease or increase, respectively, of $25 \%$ compared with baseline.

\section{Special Notes on 3D Photography}

$3 \mathrm{D}$ photography is performed in real time and generates a permanent record that is ideal for central review, for measuring and counting large numbers of tumors, for identifying new tumors in a large field, and for capturing the overall appearance of tumors. This photographic record can be used to identify novel end points of response such as global assessment of change. However, the technique cannot detect or quantitate the amount of tumor below the skin.

\section{Recommended Outcomes for Digital Calipers}

For clinical trial outcomes, the group considered the following measures as end points: length/width (linear measures) and 
calculated ellipsoid volume (table 1). The group recommended use of longest diameter (linear measure) as an outcome measure because it (1) is a clinically meaningful measure of cNF size; (2) is widely available at low cost; and (3) is the most used end point in previous studies of $\mathrm{cNF}$. Digital calipers were not recommended for measurement of $\mathrm{cNF}<5 \mathrm{~mm}$ or for measurement of height in any $\mathrm{cNF}$ given the increased variability using this technique.

\section{Feasibility}

Digital calipers are widely available, and evaluation can be performed routinely in a clinic setting. In order to minimize variability, measurements should be performed by trained personnel, ideally by the same individual throughout the study.

\section{Baseline Evaluation}

A minimum of 5 lesions representative of $\mathrm{cNF}$ should be identified as target lesions and recorded and measured at baseline. The longest diameters for each lesion should be recorded. The individual longest diameters will be used as a reference by which to characterize individual cNF response. In addition, the sum of the longest diameter for all target lesions will be calculated and reported as the baseline sum longest diameter. The baseline sum longest diameter will be used as the reference by which to characterize the collective tumor response.

\section{Response Criteria}

Caliper response criteria are defined in reference to the baseline longest diameter of individual $\mathrm{cNF}$ at study initiation. The group recommends change in longest dimension as the primary end point (table 2) and the change in the sum of longest diameter as an exploratory end point.

cNF shrinkage is defined as a relative decrease in the longest diameter of $25 \%$. cNF growth is defined as a relative increase in the longest diameter of $25 \%$. Stable size is defined as all other changes. For studies using the sum of longest diameters, cNF shrinkage or growth is defined as a relative decrease or increase, respectively, in the sum of longest diameters of $25 \%$.

\section{Special Notes on Caliper Measurements}

Caliper measurements are easily used in clinical studies. However, they are performed in real time and do not generate a permanent record. Thus, this technique does not permit central review. In addition, the technique cannot detect or qualify the amount of tumor component below the skin, or changes in appearance (e.g., coloration) during treatment. The technique is time-consuming for measurement of large numbers of tumors across the body.

\section{Overall Response Criteria and Duration of Treatment}

The REiNS International Collaboration is not recommending overall response criteria given the lack of real-world clinical trial data for cNF assessments. Because the suggested response criteria for $\mathrm{cNF}$ trials involve at least $5 \mathrm{cNF}$ for each participant, it is possible that individual cNF will have discordant responses to investigational agents. In cancer trials, overall response is used to determine the duration of treatment: patients with imaging response or stable disease typically continue treatment whereas those with progressive disease discontinue treatment. In contrast to most cancers, growth of individual $\mathrm{cNF}$ do not place participants at significantly increased risk of morbidity or mortality because these lesions do not affect critical structures and because surgical removal is an option for virtually all cNF. At this time, the criteria for removal of patients due to tumor growth are not clearly defined. In the absence of clear criteria, trialists should consider the safety profile and existing data on the median time to maximum response of investigational agents. We do not recommend the absolute requirement to remove participants from trials when $\mathrm{cNF}$ progress on therapy, particularly in the situation when there is a discordant response (i.e., when some cNF shrink and others grow compared with baseline). Instead, we recommend that trials consider specifying a fixed treatment duration based on best available information about the investigational agent under study.

These recommendations are designed to establish end points for clinical trials that seek to measure the size of $\mathrm{cNF}$ in people with NF1. It is hoped that these end points accelerate clinical trials for $\mathrm{cNF}$ and facilitate comparison across studies to identify active treatments. The recommended outcomes have not been prospectively used in cNF trials to date and the REiNS cNF Working Group expects to revise these recommendations as data from trials are published.

\section{Acknowledgment}

The authors thank the following collaborators for their participation in the REiNS cNF Working Group: Anat Stemmer-Rachamimov (Massachusetts General Hospital), Andrea Baldwin (National Cancer Institute), Andrés J. Lessing (REiNS patient representative), Ashley Cannon (University of Alabama at Birmingham, coordinating role for working group meetings), Elizabeth Schorry (Cincinnati Children's Hospital), Brigitte Widemann (National Cancer Institute), Christopher Moertel (University of Minnesota), Claas Rohl (REiNS patient representative), Dawn Siegel (Medical College of Wisconsin), Deeann Wallis (University of Alabama at Birmingham), Dominique Pichard (National Cancer Institute, coordinating role for working group meetings), Gregg Erickson (REiNS patient representative), Kaleb Yohay (New York University), Kavita Sarin (Stanford University, coordinating role for working group meeting), Khaled Ezzedine (Assistance Publique-Hôpitaux de Paris), Krista Fredrick (REiNS patient representative), Maciej Mrugala (Mayo Clinic), Michael Fisher (Children's Hospital of Philadelphia), Pamela Wolters (National Cancer Institute), Pierre Wolkenstein (Hôpital Henri-Mondor), Robert Kesterson (University of Alabama at Birmingham), Sarah Adsit (REiNS patient representative), Shannon Langmead (Johns 
Hopkins University), Sharad Verma (Johns Hopkins University), Sheilagh Maguiness (University of Minnesota), Tena Rosser (Children's Hospital Los Angeles), Victor Mautner (University Hamburg, Eppendorf), and Yemima Berman (University of Sydney). The authors also acknowledge the support of the Children's Tumor Foundation for the REiNS International Collaboration. This work was supported by an agreement from The Johns Hopkins University School of Medicine and the Neurofibromatosis Therapeutic Acceleration Program. Its contents are solely the responsibilities of the authors and do not necessarily represent the official views of The Johns Hopkins University School of Medicine.

\section{Study Funding}

Supported by the Neurofibromatosis Therapeutic Acceleration Program.

\section{Disclosure}

R.D. Thalheimer, V.L. Merker, K.I. Ly, A.H. Champlain, J.L. Sawaya, N. Askenazi, H. Herr, and J.L.W. Da report no disclosures relevant to the manuscript. J.T. Jordan is a consultant for CereXis, Inc., Health 2047, Inc., NF Network, and Navio Theragnostics; and receives royalties from Elsevier. A. Muzikansky, E. Morehouse, and F.H. Sakamoto report no disclosures relevant to the manuscript. J.O. Blakeley is the director of the Neurofibromatosis Therapeutic Acceleration Program, which funded a portion of this work; and has served as a paid consultant for AbbVie and an unpaid consultant for Springworks and AstraZeneca. R.R. Anderson reports no disclosures relevant to the manuscript. S.R. Plotkin is cofounder of NFlection Therapeutics, Inc. and of NF2 Therapeutics, Inc. and is a consultant for AstraZeneca and for SonalaSense. Go to Neurology.org/N for full disclosures.

\section{Publication History}

Received by Neurology October 9, 2020. Accepted in final form May 11, 2021.

Appendix Authors

\begin{tabular}{lll}
\hline Name & Location & Contribution \\
\hline $\begin{array}{l}\text { Raquel D. } \\
\text { Thalheimer, } \\
\text { BA }\end{array}$ & $\begin{array}{l}\text { Massachusetts General } \\
\text { Hospital, Boston }\end{array}$ & $\begin{array}{l}\text { Acquisition of data; design of } \\
\text { the study; interpretation of } \\
\text { the data; drafting the } \\
\text { manuscript for intellectual } \\
\text { content }\end{array}$ \\
\hline $\begin{array}{l}\text { Vanessa L. } \\
\text { Merker, PhD }\end{array}$ & $\begin{array}{l}\text { Edith Nourse Rogers } \\
\text { Memorial Veterans } \\
\text { Hospital, Bedford, MA }\end{array}$ & $\begin{array}{l}\text { Acquisition of data; design of } \\
\text { the study; interpretation of } \\
\text { the data; revising the } \\
\text { manuscript for intellectual } \\
\text { content }\end{array}$ \\
\hline K. Ina Ly, MD & $\begin{array}{l}\text { Massachusetts General } \\
\text { Hospital, Boston }\end{array}$ & $\begin{array}{l}\text { Acquisition of data; revising } \\
\text { the manuscript for } \\
\text { intellectual content }\end{array}$ \\
\hline $\begin{array}{l}\text { Amanda H. } \\
\text { Champlain, } \\
\text { MD }\end{array}$ & $\begin{array}{l}\text { Massachusetts General } \\
\text { Hospital, Boston }\end{array}$ & Acquisition of data \\
\hline
\end{tabular}

Appendix (continued)

\begin{tabular}{lll}
\hline Name & Location & Contribution \\
\hline $\begin{array}{l}\text { Jennifer } \\
\text { Sawaya, MD }\end{array}$ & $\begin{array}{l}\text { Massachusetts General } \\
\text { Hospital, Boston }\end{array}$ & Acquisition of data \\
\hline $\begin{array}{l}\text { Naomi L. } \\
\text { Askenazi }\end{array}$ & $\begin{array}{l}\text { Massachusetts General } \\
\text { Hospital, Boston }\end{array}$ & $\begin{array}{l}\text { Analysis and interpretation } \\
\text { of the data; revising the } \\
\text { manuscript for intellectual } \\
\text { content }\end{array}$ \\
$\begin{array}{lll}\text { Hamilton } \\
\text { Herr, BA }\end{array}$ & Massachusetts General & $\begin{array}{l}\text { Acquisition of data; analysis } \\
\text { and interpretation of the } \\
\text { data; revising the } \\
\text { manuscript for intellectual } \\
\text { content }\end{array}$ \\
\hline
\end{tabular}

Jennifer L.W. Massachusetts General Da, BA Hospital, Boston

Acquisition of data; analysis and interpretation of the data; revising the manuscript for intellectual content

\begin{tabular}{|c|c|c|}
\hline $\begin{array}{l}\text { Justin T. } \\
\text { Jordan, MD, } \\
\text { MPH }\end{array}$ & $\begin{array}{l}\text { Massachusetts General } \\
\text { Hospital, Boston }\end{array}$ & $\begin{array}{l}\text { Design of the study; } \\
\text { recruitment of participants; } \\
\text { revising the manuscript for } \\
\text { intellectual content }\end{array}$ \\
\hline $\begin{array}{l}\text { Alona } \\
\text { Muzikansky, } \\
\text { MA }\end{array}$ & $\begin{array}{l}\text { Massachusetts General } \\
\text { Hospital, Boston }\end{array}$ & $\begin{array}{l}\text { Design of the study; } \\
\text { interpretation of the data; } \\
\text { revising the manuscript for } \\
\text { intellectual content }\end{array}$ \\
\hline $\begin{array}{l}\text { Elizabeth } \\
\text { Morehouse, } \\
\text { BA }\end{array}$ & $\begin{array}{l}\text { Massachusetts General } \\
\text { Hospital, Boston }\end{array}$ & $\begin{array}{l}\text { Acquisition of data; revising } \\
\text { the manuscript for } \\
\text { intellectual content }\end{array}$ \\
\hline $\begin{array}{l}\text { Fernanda H. } \\
\text { Sakamoto, } \\
\text { MD, PhD }\end{array}$ & $\begin{array}{l}\text { Massachusetts General } \\
\text { Hospital, Boston }\end{array}$ & $\begin{array}{l}\text { Design of the study; } \\
\text { interpretation of the data; } \\
\text { revising the manuscript for } \\
\text { intellectual content }\end{array}$ \\
\hline $\begin{array}{l}\text { Jaishri O. } \\
\text { Blakely, MD }\end{array}$ & $\begin{array}{l}\text { Johns Hopkins School of } \\
\text { Medicine, Baltimore, MD }\end{array}$ & $\begin{array}{l}\text { Design and } \\
\text { conceptualization of the } \\
\text { study; interpretation of the } \\
\text { data; revising the } \\
\text { manuscript for intellectual } \\
\text { content }\end{array}$ \\
\hline $\begin{array}{l}\text { R. Rox } \\
\text { Anderson, MD }\end{array}$ & $\begin{array}{l}\text { Massachusetts General } \\
\text { Hospital, Boston }\end{array}$ & $\begin{array}{l}\text { Design and } \\
\text { conceptualization of the } \\
\text { study; interpretation of the } \\
\text { data; revising the } \\
\text { manuscript for intellectual } \\
\text { content }\end{array}$ \\
\hline $\begin{array}{l}\text { Scott R. } \\
\text { Plotkin, MD, } \\
\text { PhD }\end{array}$ & $\begin{array}{l}\text { Massachusetts General } \\
\text { Hospital, Boston }\end{array}$ & $\begin{array}{l}\text { Design and } \\
\text { conceptualization of the } \\
\text { study; interpretation of the } \\
\text { data; recruitment of } \\
\text { participants; drafting the } \\
\text { manuscript for intellectual } \\
\text { content }\end{array}$ \\
\hline
\end{tabular}

\section{References}

1. Blakeley JO, Wolkenstein $\mathrm{P}$, Widemann BC, et al. Creating a comprehensive research strategy for cutaneous neurofibromas. Neurology. 2018;91(2 suppl 1):S1-S4.

2. Jouhilahti EM, Peltonen S, Callens T, et al. The development of cutaneous neurofibromas. Am J Pathol. 2011;178(2):500-505.

3. Duong TA, Bastuji-Garin S, Valeyrie-Allanore L, Sbidian E, Ferkal S, Wolkenstein P. Evolving pattern with age of cutaneous signs in neurofibromatosis type 1: a crosssectional study of 728 patients. Dermatology. 2011;222(3):269-273.

4. Page PZ, et al.. Impact of neurofibromatosis 1 on quality of life: a cross-sectional study of 176 American cases. Am J Med Genet A. 2006;140A:1893-1898.

5. Levine SM, Levine E, Taub PJ, Weinberg H. Electrosurgical excision technique for the treatment of multiple cutaneous lesions in neurofibromatosis type I. J Plast Reconstr Aesthet Surg. 2008;61(8):958-962. 
6. Lutterodt CG, Mohan A, Kirkpatrick N. The use of electrodessication in the treatment of cutaneous neurofibromatosis: a retrospective patient satisfaction outcome assessment. J Plast Reconstr Aesthet Surg. 2016;69(6):765-769.

7. Elwakil TF, Samy NA, Elbasiouny MS. Non-excision treatment of multiple cutaneous neurofibromas by laser photocoagulation. Lasers Med Sci. 2008;23(3): 301-306.

8. Méni C, Sbidian E, Moreno JC, et al. Treatment of neurofibromas with a carbon dioxide laser: a retrospective cross-sectional study of 106 patients. Dermatology. 2015; 230(3):263-268

9. Yoshida Y, Sato N, Furumura M, Nakayama J. Treatment of pigmented lesions of neurofibromatosis 1 with intense pulsed-radio frequency in combination with topical application of vitamin D3 ointment. J Dermatol. 2007;34(4):227-230.

10. Slopis JM, Arevalo O, Bell CS, et al. Treatment of disfiguring cutaneous lesions in neurofibromatosis-1 with everolimus: a phase II, open-label, single-arm trial. Drugs $R$ D. $2018 ; 18(4): 295-302$.

11. Kim SH, Roh SG, Lee NH, Yang KM. Radiofrequency ablation and excision of multiple cutaneous lesions in neurofibromatosis type 1. Arch Plast Surg. 2013;40(1):57-61.

12. Koenig MK, Bell CS, Hebert AA, et al. Efficacy and safety of topical rapamycin in patients with facial angiofibromas secondary to tuberous sclerosis complex: the TREATMENT randomized clinical trial. JAMA Dermatol. 2018;154(7):773-780.
13. Ortonne N, Wolkenstein P, Blakeley JO, et al. Cutaneous neurofibromas: current clinical and pathologic issues. Neurology. 2018;91(2 suppl 1):S5-S13.

14. Verma SK, Riccardi VM, Plotkin SR, et al. Considerations for development of ther apies for cutaneous neurofibroma. Neurology. 2018;91(2 suppl 1):S21-S30.

15. Cannon A, Chen MJ, Li P, et al. Cutaneous neurofibromas in neurofibromatosis type I: a quantitative natural history study. Orphanet J Rare Dis. 2018;13(1):31.

16. Raffin D, Zaragoza J, Georgescou G, et al. High-frequency ultrasound imaging for cutaneous neurofibroma in patients with neurofibromatosis type I. Eur J Dermatol. 2017;27(3):260-265.

17. Chren MM, Lasek RJ, Flocke SA, et al. Improved discriminative and evaluative capability of a refined version of Skindex, a quality-of-life instrument for patients with skin diseases. Arch.Dermatol. 1997;133(11):1433-1440.

18. Ferner RE, Thomas M, Mercer G, et al. Evaluation of quality of life in adults with neurofibromatosis 1 (NF1) using the Impact of NF1 on Quality of Life (INF1-QoL) questionnaire. Health Qual Life Outcomes. 2017;15(1):34.

19. Dombi E, Ardern-Holmes SL, Babovic-Vuksanovic D, et al. Recommendations for imaging tumor response in neurofibromatosis clinical trials. Neurology. 2013;81(21 suppl 1):S33-S40.

20. Posada JG, Chakmakjian CG. Images in clinical medicine: Von Recklinghausen's disease and breast cancer. N Engl J Med. 2005;352(17):1799. 


\section{Neurology}

\section{Validating Techniques for Measurement of Cutaneous Neurofibromas: Recommendations for Clinical Trials}

Raquel D. Thalheimer, Vanessa L. Merker, K. Ina Ly, et al.

Neurology 2021;97;S32-S41 Published Online before print July 6, 2021

DOI 10.1212/WNL.0000000000012428

\section{This information is current as of July 6, 2021}

\section{Updated Information \& Services}

References

Citations

Subspecialty Collections

Permissions \& Licensing

\section{Reprints}

including high resolution figures, can be found at: http://n.neurology.org/content/97/7_Supplement_1/S32.full

This article cites 20 articles, 4 of which you can access for free at: http://n.neurology.org/content/97/7_Supplement_1/S32.full\#ref-list-1

This article has been cited by 1 HighWire-hosted articles: http://n.neurology.org/content/97/7_Supplement_1/S32.full\#\#otherartic les

This article, along with others on similar topics, appears in the following collection(s):

Neurofibromatosis

http://n.neurology.org/cgi/collection/neurofibromatosis Ultrasound

http://n.neurology.org/cgi/collection/ultrasound

Information about reproducing this article in parts (figures,tables) or in its entirety can be found online at:

http://www.neurology.org/about/about_the_journal\#permissions

Information about ordering reprints can be found online:

http://n.neurology.org/subscribers/advertise

Neurology ${ }^{\circledR}$ is the official journal of the American Academy of Neurology. Published continuously since 1951, it is now a weekly with 48 issues per year. Copyright () 2021 American Academy of Neurology. All rights reserved. Print ISSN: 0028-3878. Online ISSN: 1526-632X.



